\title{
Vasculopathy of Aging and the Revised Cardiovascular Continuum
}

\author{
Su-A Kim ${ }^{a}$ Jeong Bae Park ${ }^{a}$ Michael F. O'Rourke ${ }^{b}$ \\ a Division of Cardiology, Department of Medicine, Cheil General Hospital, Dankook \\ University, College of Medicine, Seoul, Republic of Korea; ${ }^{b}$ Victor Chang Cardiac Research \\ Institute, St. Vincent's Clinic, University of New South Wales, Sydney, N.S.W., Australia
}

\section{Key Words}

Artery $\cdot$ Aging $\cdot$ Pulse wave $\cdot$ Cardiovascular disease

\begin{abstract}
There have been attempts to explain the process of developments in overt cardiovascular disease, resulting in the presentation of the classic cardiovascular disease continuum and the aging cardiovascular continuum. Although the starting points of these two continua are different, they meet in the midstream of the cycle and reach a consensus at the end of the process. The announcement of the aging cardiovascular continuum made both continua complete, explaining the cardiovascular events in patients without atherosclerotic cardiovascular disease with aging. Impairment of the vascular structure by pulse wave and reflected wave is considered the cause of aortic damage, which influences the development of ischemic heart disease and the development of overt renal disease or cerebrovascular disease. The pathophysiology of vascular aging through pulse wave and its effect on other organs was discussed with Prof. Michael F. O'Rourke who devised the aging cardiovascular continuum.
\end{abstract}

(C) 2015 S. Karger AG, Basel

\section{Introduction}

This paper was written based on an interview with Dr. Michael F. O’Rourke. He is a director of Victor Chang Cardiac Research Institute, St. Vincent's Clinic, University of New South Wales, Sydney, N.S.W., Australia. He is the world's leading expert in cardiovascular physiology and medicine. He is co-author of the standard reference text book Blood Flow in Arteries: Theoretical, Experimental and Clinical Principles and the co-founder of AtCor who invented the technology on which SphygmoCor is based.

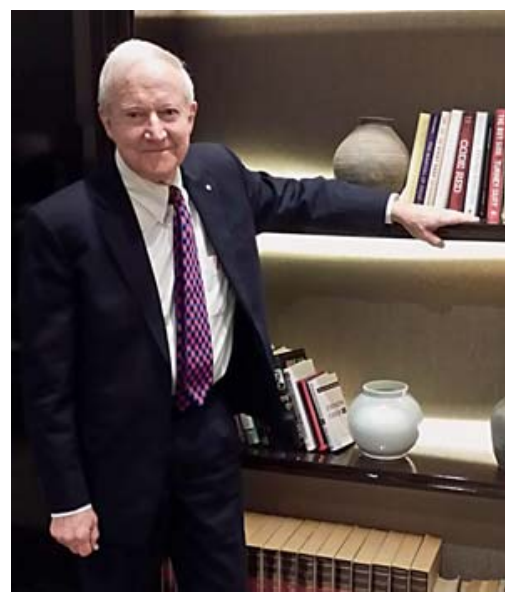


Dr. O'Rourke is the recipient of a number of scientific awards (among which are the Simon Dack Annual Award for services to the Journal of American College of Cardiology, Honorary Life Membership, NSW Division Heart Foundation, and Life Achievement Award, European Artery Association), the author of 484 peer-reviewed papers, and editorial board member for international peer-reviewed scientific journals including the Journal of Hypertension, Journal of the American College of Cardiology, and Canadian Journal of Cardiology and Hypertension.

'The aging cardiovascular continuum' was published by Dr. Michael F. O'Rourke and approaches cardiovascular disease with vascular aging [1] 4 years after the classic 'cardiovascular disease continuum' has been presented in 2006. Dzau and colleagues [2,3] published two articles about the cardiovascular disease continuum, explaining the process of developments in coronary artery disease. The cardiovascular disease continuum of Dzau and colleagues [2,3] starts with the risk factors for coronary artery disease, such as hypertension, diabetes mellitus, dyslipidemia, smoking and obesity. Then, they proceed to atherosclerosis, myocardial ischemia, coronary thrombosis and myocardial infarction, which cause congestive heart failure and end-stage heart disease. The aging cardiovascular continuum of Dr. O'Rourke starts with aging itself. He says that aortic pulsation - repetitive stretches and relaxations of the aorta - reaching 3 billion cycles in people in their $80 \mathrm{~s}$, is the cause of aortic damage and consequently of cardiovascular disease.

Although the two continua look different, they meet in the midstream of each continuum, where overt cardiovascular disease develops, and share the process for congestive heart failure and end-stage heart disease following myocardial infarction. The classic continuum explains that cardiovascular disease develops from atherosclerosis, and therefore, the cause of heart failure in patients without atherosclerotic coronary artery disease and without risk factors for atherosclerosis cannot be explained by it. Then, the continuum of Dr. O'Rourke was devised. With these two continua together, a more comprehensive explanation for the development of end-stage heart disease is possible in both patients with atherosclerosis and in those who do not suffer from atherosclerotic diseases or their risk factors (fig. 1). The aging cardiovascular continuum also explains the cause of cardiovascular events in the group of patients who are more fragile to end-stage heart disease with aging as well as the cause of frequent microvascular diseases of other organs, predominantly the brain and kidneys. Therefore, it is important to understand the role of vascular aging in the cardiovascular continuum.

\section{The Concept of Vasculopathy of Aging in the Traditional Cardiovascular Continuum}

The aging cardiovascular continuum is the result of pulse wave. In the 80 years of average human life, the heart pulses up to 3 billion times, which influences the aorta. The aorta repetitively stretches and relaxes with every beat of the heart. Dilatation of the aorta (even up to $15 \%$ of the diameter in young people) through pulsation [4] damages the small elastin fibers in the aorta [4,5] and makes the aorta more brittle, fragile and wider with age [6]. Then, the aorta stiffens [7-9], and the pressure by the pulsating blood flow becomes higher with less stretches of the aorta [7]. Systolic hypertension, left ventricular hypertrophy and myocardial ischemia with impaired myocardial blood supply develop with the change of the aorta [9]. In other words, the aging cardiovascular disease continuum begins with the pulse wave in the cardiac cycle, which causes mechanical stretching of the vessels over a long period of time [1].

The pulse wave is generated by the ejecting blood flow of the heart into the aorta, which comprises a wave of pressure. The flow wave is pulsatile so that it acts like a shear stress trav- 


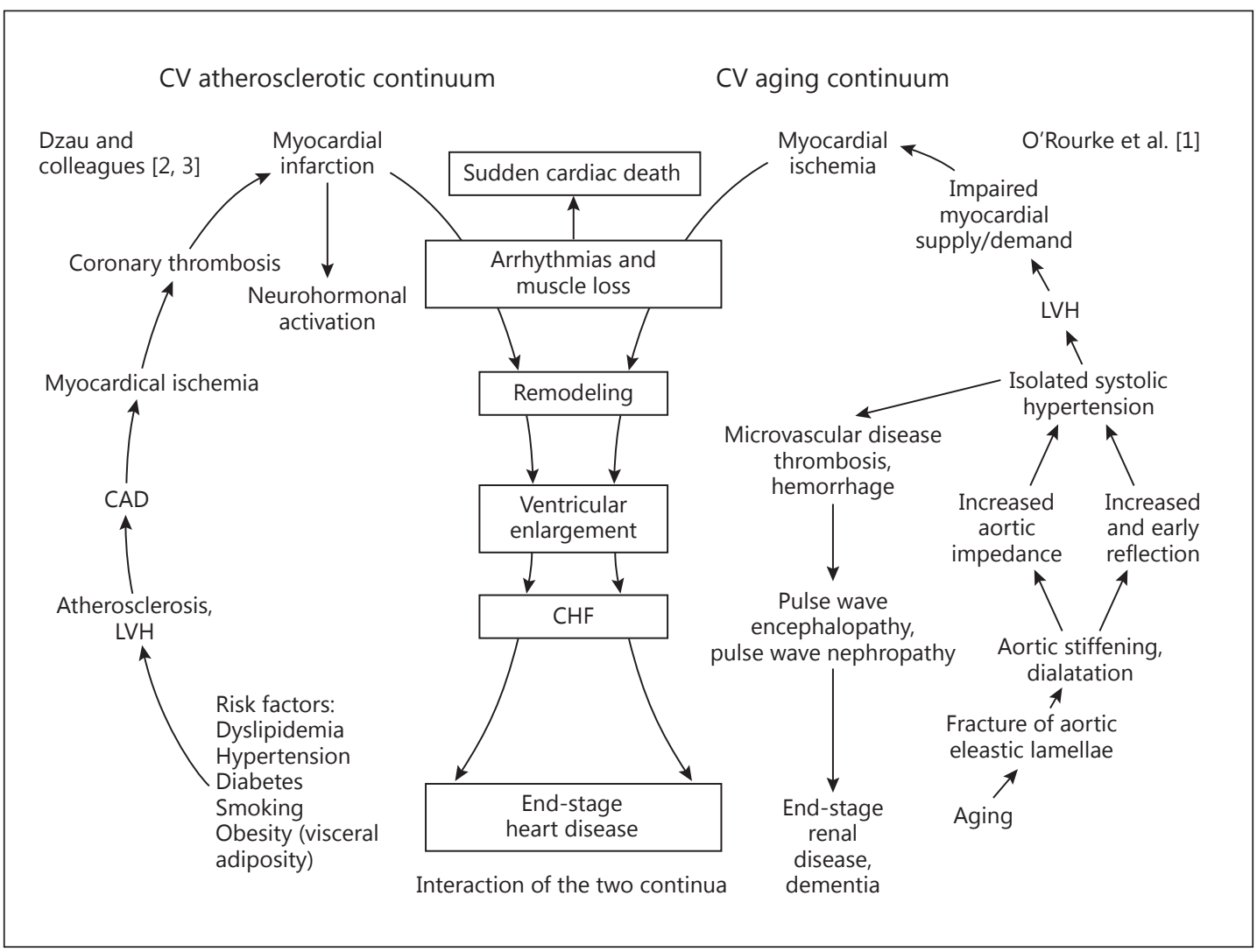

Fig. 1. Interaction of the traditional atherosclerotic cardiovascular continuum (left) and the aging continuum (right). $\mathrm{CV}=$ Cardiovascular; $\mathrm{CAD}=$ coronary artery disease; $\mathrm{LVH}=$ left ventricular hypertrophy; $\mathrm{CHF}=$ congestive heart failure.

eling longitudinally along the vessels tending to sheer off the endothelial cells along the path of the blood flow running backward and forward into different organs or different parts of the body irrespective of the pulse wave pressure which stretches the arterial wall circumferentially and causes arterial wall damage [1]. Besides, the pulse wave pressure is reflected back to the heart and the other organs, causing overt cardiovascular disease, renal and cerebrovascular disease [10]. When the reflected wave reaches the aorta during systole, it will boost the systolic pressure as well as the pressure in the brain and other organs. Therefore, it is emphasized that the central aorta provides better measurements of blood pressure compared to peripheral arteries [11]. Furthermore, unlike small vessels with low resistance that get more of the pulsatile nature of pressure from the blood flow, the aorta cannot absorb the pulse [12] and transfers these pulsations of flow and pressure further into the smallest blood vessels $[13,14]$.

\section{Differences in Isolated Systolic Hypertension between Youth and the Elderly}

In the Chicago Heart Association Detection Project in Industry, people were classified into 5 groups according to the level of systolic and diastolic blood pressure, normal or low blood pressure, upper normal blood pressure, isolated systolic hypertension with normal diastolic pressure, and isolated diastolic hypertension with normal systolic pressure, systolic 
and diastolic hypertension. It was found that the isolated systolic hypertension is much more benign in youth than in the elderly. For men aged between 18 and 49 years, the isolated systolic hypertension group showed the same cardiovascular outcome as the group with normal blood pressure and had a much better outcome than people in the same age group with isolated diastolic hypertension or systolic and diastolic hypertension, although it was not as definite in female patients. However, in the elderly, isolated systolic hypertension was more dangerous than systolic and diastolic hypertension in males as well as in females [15, 16]. This can be explained by wave reflection [17]. Raised systolic pressure in people below the age of 60 is usually due to the early systolic peak, which is boosted by the wave reflection in peripheral arteries; however, in the elderly, it is the second peak about $200 \mathrm{~ms}$ after the beginning of the wave which is elevated, so the pressure wave forms are entirely different in these two groups [18].

The European guidelines for hypertension in 2013 [19] pointed out that young people are being diagnosed as hypertensive only based on their elevated systolic pressure, even if they are otherwise perfectly healthy. The European guidelines suggested that central blood pressure be measured for the possibility of excessively amplified brachial blood pressure due to the narrow highly 'spiked' pulse wave. Besides, there is strong evidence for treating isolated systolic hypertension in elderly people over the age of 60 whose hypertension is due to stiffening of the arteries, resulting in a definite reduction in cardiovascular events; however, there is no evidence for treating isolated systolic hypertension in people under the age of 60 [19]. These results may change the idea of isolated systolic hypertension and thus the management of other guidelines for hypertension. The European guidelines have made a start.

\section{Pulse Wave Nephropathy and Pulse Wave Encephalopathy}

In the course of our lives, the brain takes about $20 \%$ of the cardiac output, and the kidneys together take another $20 \%$. They are relatively small organs, but a lot of blood flows through them [20]. They have small vessels with low resistance [21] in order that the blood flow is very fast. As a consequence of this low resistance, more flow with the pulsatile nature of pressure gets into the brain and kidney, and into their small arteries $[10,14]$. With age, and with changes in the aorta followed by increased pulse wave velocity [22], these pulsations in flow and pressure are further transferred into the smallest blood vessels in the brain and kidney [23] without absorption of pressure from the aorta, causing microvascular changes $[23,24]$. There, with the stretching of the tiny arteriolar walls and the development of little aneurysmal ruptures and microthrombi, these small vessels lead to the condition which is called 'pulse wave encephalopathy' for the brain and 'pulse wave nephropathy' for the kidney, leading to end-stage renal disease, dementia, etc. The lesions where the pulse wave forms the high flow pulsation appeared to be enhanced, with a higher signal in the brain MRI being explained as 'pulse wave encephalopathy' [25-27].

\section{The Role of Pulse or Flow in Stroke Development}

There is a chance that the different levels of pulse wave velocity and pressure augmentation even with the same level of blood pressure can have different impacts on cerebrovascular outcome, as for example in the pathologic conditions of sickle cell anemia or in postneurosurgical patients. Patients with sickle cell anemia are very prone to thrombotic strokes especially when they have a very low red blood cell count [28]. They show full pulse flow and pressure flow, which impair the endothelium and cause a thrombus in the arteries. Their 
pulse wave velocities rise to even twice the normal peak. Pulse wave velocities at such levels are highly related to the risk of stroke, which can be reduced by treating the anemia at that stage and preventing the peak flow from getting as high as in patients who have not been treated in that way. In the case of increased intracranial pressure after neurosurgery or brain trauma, which causes secondary changes in the blood vessels and the brain, the increased intracranial pressure also presses on the arteries from the outside and narrows the arteries so that with normal flow levels, the velocity rises to the same levels as or higher [29] than those in children with sickle cell anemia. Brain damage also develops with increased intracranial pressure. Patients who have recovered from a subarachnoid hemorrhage are another example. Although these patients may have recovered from the hemorrhage, they are more prone to develop infarcts in the brain at a distance from where the original problem occurred. This may also be related to the flow wave forming in the brain. It is expected that the development of secondary strokes can be reduced in these patients with the control of vascular remodeling after the primary event.

\section{The Relation between Dementia and Pulse Wave}

Dementia is also related to pulse wave blood flow. Alzheimer's disease is generally thought to be the result of an atherosclerotic change in cerebral vessels and amyloid plaques. However, it was suggested that microbleeding in the brain as a consequence of vessel degeneration and rupture over a period of decades could be the cause of dementia [30]. Hemorrhages develop into what are recognized as amyloid- $\beta$ plaques.

\section{Differences in Microvascular Dysfunction in Coronary Arteries between the Brain and the Kidneys}

Microvascular dysfunction in coronary arteries in the brain and the kidneys seems to be entirely different. In these small vessels, coronary artery disease virtually does not exist. The heart muscle and the blood vessels of the heart are spared from the high pulsation for they do not confront the reflection of the flow wave because coronary arteries to left ventricular myocardium are compressed during systole as the heart is actually pumping. Only when the heart is relaxed, during diastole, are they exposed to the pressure, which helps coronary perfusion. Instead, when aortic stiffening proceeds with aging, the wave reflection augments the late systolic pressure, not the diastolic pressure of the aorta, and therefore, the coronary flow decreases. Simultaneously, aortic stiffening causes an increase in aortic pressure through stiffening itself and an early return of wave reflection, which leads to left ventricular hypertrophy and an increase in oxygen demand. Both an increased oxygen demand and a decrease in coronary perfusion predispose myocardial ischemia [31,32].

\section{Detection of the Vasculopathy of Aging}

The traditional way to assess arterial function is using pulse wave velocity, which measures the degree of arterial stiffness and is thought to be the best way to date $[8,22]$. Although it does not directly express the arterial function of each organ, pulse wave velocity is correlated with high vascular complications of stroke or heart failure [33-35], meaning that the aorta is not only stiff due to the disease, but conducts the cardiac impulse more quickly, and reflected waves return to the heart earlier in the cardiac cycle. 


\section{Treatment of Kidney and Brain Disease with the Concept of Pulse Wave Vasculopathy}

There have not been enough discussions about the issue of pulse wave vasculopathy treatment. However, we think that aortic stiffening is the key to most of the brain and certainly cardiac diseases that occur with aging, due to its character of generation with aging.

How can we prevent this rapid aging process? Angiotensin-converting enzyme inhibitors were discussed in this respect. There is some evidence that angiotensin-converting enzyme inhibitor drugs may delay the progression of aortic stiffening in patients with renal failure and also prevent a progressive increase in aortic pulse wave velocity [36], thus being a beneficial drug for preventing dementia. Nitrates, on the other hand, reduce wave reflection without reducing a similar effect on blood pressure [37] and are also expected to have a beneficial effect on isolated systolic hypertension [38], through reducing aortic and left ventricular systolic pressure while maintaining diastolic and left ventricular perfusion pressure.

\section{Conclusion}

The vascular aging continuum is an extended idea of the cardiovascular continuum, described by Dzau and colleagues [2,3] in 2006, which merges aging vasculopathy in the brain and kidneys and atherosclerotic coronary heart disease as well as heart failure. This idea more clearly explains the dominance of macrovascular and microvascular arterial disease in prolonged life.

\section{Acknowledgements}

We deeply thank Ms. Jina Lee and Yura Kim for their transcription of the tape recording.

\section{Disclosure Statement}

The authors declare that they have no conflicts of interest.

\section{References}

1 O'Rourke MF, Safar ME, Dzau V: The cardiovascular continuum extended: aging effects on the aorta and microvasculature. Vasc Med 2010;15:461-468.

-2 Dzau VJ, Antman EM, Black HR, Hayes DL, Manson JE, Plutzky J, et al: The cardiovascular disease continuum validated: clinical evidence of improved patient outcomes. 2. Clinical trial evidence (acute coronary syndromes through renal disease) and future directions. Circulation 2006;114:2871-2891.

-3 Dzau VJ, Antman EM, Black HR, Hayes DL, Manson JE, Plutzky J, et al: The cardiovascular disease continuum validated: clinical evidence of improved patient outcomes. 1. Pathophysiology and clinical trial evidence (risk factors through stable coronary artery disease). Circulation 2006;114:2850-2870.

4 Boutouyrie P, Laurent S, Benetos A, Girerd XJ, Hoeks AP, Safar ME: Opposing effects of ageing on distal and proximal large arteries in hypertensives. J Hypertens Suppl 1992;10:S87-S92.

5 Virmani R, Avolio AP, Mergner WJ, Robinowitz M, Herderick EE, Cornhill JF, et al: Effect of aging on aortic morphology in populations with high and low prevalence of hypertension and atherosclerosis. Comparison between occidental and Chinese communities. Am J Pathol 1991;139:1119-1129.

6 O'Rourke MF, Hashimoto J: Mechanical factors in arterial aging: a clinical perspective. J Am Coll Cardiol 2007; 50:1-13.

7 Lakatta EG: Arterial and cardiac aging: major shareholders in cardiovascular disease enterprises. 3. Cellular and molecular clues to heart and arterial aging. Circulation 2003;107:490-497.

-8 Lakatta EG, Levy D: Arterial and cardiac aging: major shareholders in cardiovascular disease enterprises. 1. Aging arteries: a 'set up' for vascular disease. Circulation 2003;107:139-146. 
-9 Lakatta EG, Levy D: Arterial and cardiac aging: major shareholders in cardiovascular disease enterprises. 2. The aging heart in health: links to heart disease. Circulation 2003;107:346-354.

10 Nichols W, O'Rourke M, Vlachopoulos C: McDonald's Blood Flow in Arteries: Theoretical, Experimental and Clinical Principles. Boca Raton, CRC Press, 2011.

11 Tomiyama H, O’Rourke M F, Hashimoto H, Matsumoto C, Odaira M, Yoshida M, et al: Central blood pressure: a powerful predictor of the development of hypertension. Hypertens Res 2013;36:19-24.

12 Safar ME, O’Rourke MF: Arterial Stiffness in Hypertension. Handbook of Hypertension. Edinburgh, Elsevier, 2006, vol 23.

13 Christensen KL, Mulvany MJ: Location of resistance arteries. J Vasc Res 2001;38:1-12.

14 Schofield I, Malik R, Izzard A, Austin C, Heagerty A: Vascular structural and functional changes in type 2 diabetes mellitus: evidence for the roles of abnormal myogenic responsiveness and dyslipidemia. Circulation 2002;106:3037-3043.

15 Yano Y, Stamler J, Garside DB, Daviglus ML, Franklin SS, Carnethon MR, et al: Isolated systolic hypertension in young and middle-aged adults and 31-year risk for cardiovascular mortality: the Chicago Heart Association Detection Project in Industry study. J Am Coll Cardiol 2015;65:327-335.

-16 Rutan GH, Kuller LH, Neaton JD, Wentworth DN, McDonald RH, Smith WM: Mortality associated with diastolic hypertension and isolated systolic hypertension among men screened for the Multiple Risk Factor Intervention Trial. Circulation 1988;77:504-514.

17 Borlaug BA, Melenovsky V, Redfield MM, Kessler K, Chang HJ, Abraham TP, et al: Impact of arterial load and loading sequence on left ventricular tissue velocities in humans. J Am Coll Cardiol 2007;50:1570-1577.

18 Wilkinson IB, Franklin SS, Hall IR, Tyrrell S, Cockcroft JR: Pressure amplification explains why pulse pressure is unrelated to risk in young subjects. Hypertension 2001;38:1461-1466.

19 O’Rourke MF, Adji A: Guidelines on guidelines: focus on isolated systolic hypertension in youth. J Hypertens 2013;31:649-654.

20 O’Rourke MF, Safar ME: Relationship between aortic stiffening and microvascular disease in brain and kidney: cause and logic of therapy. Hypertension 2005;46:200-204.

21 Heistad DD: What's new in the cerebral microcirculation? Landis Award lecture. Microcirculation 2001;8: 365-375.

22 Laurent S, Cockcroft J, Van Bortel L, Boutouyrie P, Giannattasio C, Hayoz D, et al: Expert consensus document on arterial stiffness: methodological issues and clinical applications. Eur Heart J 2006;27:2588-2605.

-23 Ruilope LM, Rosei EA, Bakris GL, Mancia G, Poulter NR, Taddei S, et al: Angiotensin receptor blockers: therapeutic targets and cardiovascular protection. Blood Press 2005;14:196-209.

24 Lammie GA, Brannan F, Slattery J, Warlow C: Nonhypertensive cerebral small-vessel disease. An autopsy study. Stroke 1997;28:2222-2229.

-25 Henry Feugeas MC, De Marco G, Peretti, II, Godon-Hardy S, Fredy D, Claeys ES: Age-related cerebral white matter changes and pulse-wave encephalopathy: observations with three-dimensional MRI. Magn Reson Imaging 2005;23:929-937.

26 Bateman GA, Levi CR, Schofield P, Wang Y, Lovett EC: Quantitative measurement of cerebral haemodynamics in early vascular dementia and Alzheimer's disease. J Clin Neurosci 2006;13:563-568.

27 Bateman GA: Pulse wave encephalopathy: a spectrum hypothesis incorporating Alzheimer's disease, vascular dementia and normal pressure hydrocephalus. Med Hypotheses 2004;62:182-187.

28 DeBaun MR, Sarnaik SA, Rodeghier MJ, Minniti CP, Howard TH, Iyer RV, et al: Associated risk factors for silent cerebral infarcts in sickle cell anemia: low baseline hemoglobin, sex, and relative high systolic blood pressure. Blood 2012;119:3684-3690.

-29 Kim MO, Adji A, O’Rourke MF, Avolio AP, Smielewski P, Pickard JD, et al: Principles of cerebral hemodynamics when intracranial pressure is raised: lessons from the peripheral circulation. J Hypertens 2015;33:12331241.

-30 Birkenhäger WH, Forette F, Staessen JA: Dementia and antihypertensive treatment. Curr Opin Nephrol Hypertens 2004;13:225-230.

-31 Buckberg GD, Fixler DE, Archie JP, Hoffman JI: Experimental subendocardial ischemia in dogs with normal coronary arteries. Circ Res 1972;30:67-81.

32 Hoffman JI, Buckberg GD: The myocardial supply:demand ratio - a critical review. Am J Cardiol 1978;41:327332.

-33 Lacy PS, O’Brien DG, Stanley AG, Dewar MM, Swales PP, Williams B: Increased pulse wave velocity is not associated with elevated augmentation index in patients with diabetes. J Hypertens 2004;22:1937-1944.

34 Laurent S, Boutouyrie P, Asmar R, Gautier I, Laloux B, Guize L, et al: Aortic stiffness is an independent predictor of all-cause and cardiovascular mortality in hypertensive patients. Hypertension 2001;37:1236-1241.

-35 Mattace-Raso FU, van der Cammen TJ, Hofman A, van Popele NM, Bos ML, Schalekamp MA, et al: Arterial stiffness and risk of coronary heart disease and stroke: the Rotterdam Study. Circulation 2006;113:657-663.

-36 Guerin AP, Blacher J, Pannier B, Marchais SJ, Safar ME, London GM: Impact of aortic stiffness attenuation on survival of patients in end-stage renal failure. Circulation 2001;103:987-992.

-37 Stokes GS, Ryan M, Brnabic A, Nyberg G: A controlled study of the effects of isosorbide mononitrate on arterial blood pressure and pulse wave form in systolic hypertension. J Hypertens 1999;17:1767-1773.

38 Abad-Perez D, Novella-Arribas B, Rodriguez-Salvanes FJ, Sanchez-Gomez LM, Garcia-Polo I, Verge-Gonzalez C, et al: Effect of oral nitrates on pulse pressure and arterial elasticity in patients aged over 65 years with refractory isolated systolic hypertension: study protocol for a randomized controlled trial. Trials 2013;14: 388. 